\title{
Three new species of Acanthocephala from Acanthogyrus (Acanthosentis) (Acanthocephala: Quadrigyridae) from tinfoil barb fish, Barbonymus schwanenfeldii in Lake Kenyir, Terengganu, Malaysia
}

\author{
Mohd-Agos, S. ${ }^{1}$, Mohd-Husin, N. ${ }^{1}$, Zakariah, M.I. ${ }^{1}$, Yusoff, N.A.H. ${ }^{1}$, Wahab, W. ${ }^{1}$, Jones, J.B. ${ }^{2}$ \\ Hassan, M. ${ }^{{ }^{*}}$ \\ ${ }^{1}$ Higher Institution Centre of Excellence (HICoE), Institute of Tropical Aquaculture and Fisheries, Universiti Malaysia Terengganu, \\ 21030 Kuala Terengganu, Terengganu, Malaysia \\ ${ }^{2}$ School of Veterinary and Life Sciences, Murdoch University, South Street, Perth WA6150, Australia \\ *Corresponding author: marina@umt.edu.my
}

\section{ARTICLE HISTORY}

Received: 17 December 2020

Revised: 18 May 2021

Accepted: 18 May 2021

Published: 30 September 2021

\begin{abstract}
This study was carried out in order to identify acanthocephalan species complexes, based on morphological variability, infecting Barbonymus schwanenfeldii from Lake Kenyir, Terengganu, Malaysia. Acanthocephala were fixed in ethanol, stained with aceto-carmine and studied morphologically by using a light microscope. Variation in morphological traits such as proboscis, proboscis receptacle, egg, testes shape and location, number of hooks and cement gland has been traditionally used to diagnose the acanthocephalans species but the delimitations between closely related species are still confusing and are always questionable among taxonomists. Molecular analysis was used for support the identification. Morphological variability prospecting reveals the presence of three different new species complexes from the subgenus Acanthosentis by referring published taxonomic keys. These new species may be distinguished from the other 46 described species of Acanthosentis by having six unique structures: the presence of an anterior parareceptacle structure (PRS); vaginal sleeve structure; a paired lateral, cone-shaped, muscular jacket surrounding the vagina; alternating pattern and size of proboscis hooks, variation in proboscis size and shape; the presence of the circular collar ring around the neck between the proboscis and trunk and lastly the presence of a muscular-like structure attached to the collar ring on the proboscis. These acanthocephalans found in the intestine of $B$. schwanenfeldii in Kenyir Lake Malaysia represent new species, named Acanthogyrus (Acanthosentis) kenyirensis n.sp., A. (A.) terengganuensis n.sp. and A. (A.) tembatensis n. sp.
\end{abstract}

Keywords: Acanthocephalan; Acanthosentis; new species; parasite; Lake Kenyir.

\section{INTRODUCTION}

Kenyir Lake, Malaysia is the largest artificial lake in South East Asia, created primarily for power generation in 1985. More than 28 species of fish are commonly found in Lake Kenyir. Several exotic species have also recently been introduced to the lake and floating cage culture project has been initiated. This present study focused on the Tinfoil Barb Barbonymus schwanenfeldii because they are very common and receive less attention than commercial fish. However, diseases or parasites in wild fish such as $B$. schwanenfeldii have been a great concern since the aquaculture activities began.

Acanthocephala are known as thorny-headed worms, characterized by the presence of an evertable proboscis, armed with hooks and spines. This parasite are obligate endoparasites, commonly attached to the intestine of the definitive host (Taraschewski, 1989a, 1989b, 2000). They have complex life cycles, involving a number of intermediate hosts, including arthropods while fishes, amphibians, birds and mammals act as the definitive hosts (Crompton \& Nickol, 1985). There has been no comprehensive study on Acanthocephala in fish from Kenyir Lake. However, previous studies showed records for two species of aquatic acanthocephalan in Malaysia, from the genus Pallisentis and Acanthogyrus. Acanthosentis partispinus, discovered from intestine of the Hampala barb, Hampala macrolepidota was the first record of the subgenus Acanthosentis in Tasik Bera, Malaysia (Furtado, 1963).

Golvan (1959) synonymized Acanthosentis with Acanthogyrus and reduced Acanthosentis to the subgenus based on the number of hooks on the proboscis: the nominal subgenus has three circles of eight proboscis hooks each and Acanthosentis has three circles of six hooks each. Amin 
(2005) evaluated the status of Acanthosentis and provided a taxonomic key to the sub-genus. However, identification of acanthocephalans is still confusing and is always questionable among taxonomists due to the lack of characters available for morphology analysis; their morphological similarity, and overlapping morphological variation. Detailed, comprehensive analyses of morphology must be carried out to reveal how much variation exits in each character and which characters can be used for species recognition. But there are still many species of acanthocephalan are undiscovered yet. This study presents a description of three new species of Acanthocephala from B. schwanenfeldii in Kenyir Lake.

\section{MATERIALS AND METHODS}

\section{Sampling area, host and parasite collection}

Wild B. schwanenfeldii $(n=297$; weight $=55.8 \pm 48.7 \mathrm{~g}$; length $=$ $15.6 \pm 4.87 \mathrm{~cm})$ were caught using fishing nets from Terengganu

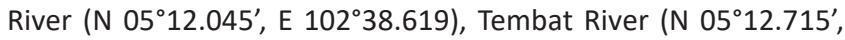
E $102^{\circ} 38.435^{\prime}$ ) and Petuang River (N $05^{\circ} 12.469^{\prime}$, E $102^{\circ} 39.379$ ). Fish were sedated by using ice. The fish were dissected and observed for acanthocephalans in the gastrointestinal tract. Acanthocephalans were extended in fresh water until proboscis were everted then preserved in $70 \%$ ethanol for further morphological study (Berland, 2005).

\section{Morphological descriptions of parasite}

Acanthocephalans were stained using aceto-carmine and dehydrated in an ethanol series, cleared with clove oil and mounted on slides with Canada balsam (Berland, 2005). Morphological description was based on previously described species of Acanthocephala. Measurement of trunk, proboscis hooks, proboscis receptacle, lemniscus, uterine bell, vagina, testes (anterior and posterior testis) and cement gland were taken from matured specimens using an Advanced Research Compound Microscope (Nikon Eclipse $80 ß$, Japan). Variation in morphological characteristics such as proboscis shape, number of hooks, proboscis receptacle shape, testes shape and location, kind of cement gland and egg shape has been used to identify the acanthocephalans species. Thus, the length and width of body, proboscis, anterior, middle and posterior hooks of proboscis were recorded accordingly Petrochenko (1956) to provide a series of variation for morphometric data. Hooks on the proboscis were arranged in longitudinal rows. Body length where measured was by trunk length which does not include neck, proboscis or everted male bursa. All measurements are presented in micrometers (ìm).

\section{Molecular analyses method}

Total genomic DNA from each individual was extracted using the DNeasy Blood and Tissue Kit (Qiagen, Valencia, California) according to the manufacturer's instructions. Polymerase Chain Reaction amplification of ITS rDNA gene was performed in a total volume of $25 \mu$ l containing $\sim 20 \mathrm{ng} / \mu \mathrm{l}$ genomic DNA, $0.4 \mu \mathrm{l}$ of each primer $(100 \mu \mathrm{M}), 12.5 \mathrm{ul}$ of $2 X$ MyTaq-Mix (Bioline) and double-distilled water. The primers used were BD1 (50-GTC GTA ACA ACG TTT CCG TA-30) and BD2 (50-TAT GCT TAA (G/A) TT CAG CGG GT-30) (Luton et al., 1992). The PCR reaction was performed in a thermal cycler (Eppendorf, Germany) with the following program: initial denaturation at $94^{\circ} \mathrm{C}$ for $4 \mathrm{~min}$, followed by 35 cycles at $94^{\circ} \mathrm{C}$ for $1 \mathrm{~min}$, annealing at $54^{\circ} \mathrm{C}$ for $1 \mathrm{~min}$ and extension at $72^{\circ} \mathrm{C}$ for $1 \mathrm{~min} 50 \mathrm{sec}$ and final extension at $72^{\circ} \mathrm{C}$ for $10 \mathrm{~min}$ according to Song et al. (2014) with some modifications on annealing temperature. The PCR products were visualized on a $1.7 \%(\mathrm{w} / \mathrm{v})$ agarose gel, stained by SYBR SAFE and was viewed under UV light in a gel documentation system. Successful PCR products were sent for DNA sequencing (First Base Laboratories Sdn. Bhd., Malaysia).

All sequence was edited and aligned using ClustalW implemented in MEGA 7.0 (Tamura et al., 2011). Confirmation of species identification were done by comparing with other sequences of acanthocephalan from GenBank (http://blast. ncbi.nlm.nih.gov) (Benson et al., 2012) using the BLASTN. All the aligned sequences were deposited into GenBank under the accession number; $A$. (A) kenyirensis n. sp. (MK069588), $A$. (A) terengganuensis $\mathrm{n}$. sp. (MK184204) and $A$. (A) tembatensis $\mathrm{n}$. sp. (MK184205). A p-distance measure was employed to infer genetic distances between species. A Maximum Likelihood tree was generated with a rotiferan Brachionus plicatilis as an outgroup based on the sister taxa status of Rotifera and Acanthocephalan (Amin et al., 2016). Confidence levels at each node assessed by 10000 bootstrap replications. The best fitting evolutionary model for phylogenetic analysis was determined using MEGA 7 (Kumar et al., 2016) based on Bayesian and Akaike Information Criterion, Tamura 3-parameter was consider as the best-fit substitution model. A total of 21 acanthocephalans parasites species were also included in the analysis for comparison (Table 1).

\section{RESULTS}

Acanthocephalans were identified to the genus Acanthogyrus (Thapar, 1927) and subgenus Acanthosentis (Verma \& Datta, 1929). These worms were belonging to class Eoacanthocephala (Van Cleave, 1948) which have a single syncytial cement gland, containing a relatively small number of giant nuclei and a single cement reservoir. Genera are commonly recognizable on the basis of distinct differences in the formulae of the proboscis armature (Van Cleave, 1951) while species differences are comparatively minor morphological features which involved relative or absolute size of the body or of its component parts. The taxonomy of the subgenus Acanthosentis, infecting the host intestine of B. schwanenfeldii (Bleeker, 1854) in Kenyir Lake, Terengganu, Malaysia, were detailed as follows:

\section{Description of Acanthogyrus (Acanthosentis) kenyirensis n.sp.}

Type-host: Barbonymus schwanenfeldii (Cyprinidae); Tinfoil Barb; Lampam sungai

Type-locality: Tembat River Kenyir Lake, Terengganu, Malaysia Site of infection: Intestine

Type-specimens: Holotype male; allotype female

Etymology: The new species is named for the location they were found; Kenyir Lake

Voucher specimens: One complete holotype male and one complete allotype female of Acanthogyrus (Acanthosentis) kenyirensis. n. sp. were deposited in Pusat Rujukan dan Repositori Laut China Selatan, Insitut Oseanografi \& Sekitaran (INOS), Universiti Malaysia Terengganu (UMT) under collection numbers UMTAcant 0001 (holotype male) and UMTAcant 0002 (allotype female)

Representative DNA sequences: Acanthogyrus (Acanthosentis) kenyirensis n.sp are deposited in the GenBank database under accession number: MK069588 (ITS sequences)

General. Quadrigyridae, Pallisentinae, with characters of Acanthogyrus (Thapar, 1927) and subgenus Acanthosentis (Verma \& Datta, 1929) as diagnosed by Amin (2005). Sexual dimorphism well marked; females are larger than males. Trunk small, curved ventral, slightly enlarged in middle of 
Table 1. List of the species of acanthocephalans parasites and outgroup used in the phylogenetic analyses on subgenus Acanthosentis using sequences of the ITS-1, $5.8 \mathrm{~S}$ and ITS-2

\begin{tabular}{|c|c|c|}
\hline Species & Family & Accession Number \\
\hline Acanthosentis cheni & Quadrigyridae & $J X 960752.1$ \\
\hline Acanthosentis kenyirensis & Quadrigyridae & MK069588 \\
\hline Acanthosentis terengganuensis & Quadrigyridae & MK184204 \\
\hline Acanthosentis tembatensis & Quadrigyridae & MK184205 \\
\hline Atactorhynchus duranguensis & Neoechinorhynchidae & KY077115.1 \\
\hline Neoechinorhynchus mamensii & Neoechinorhynchidae & KC004198.1 \\
\hline Neoechinorhynchus golvani & Neoechinorhynchidae & KC004219.1 \\
\hline Neoechinorhynchus sp. & Neoechinorhynchidae & KY077111.1 \\
\hline Mayarhynchus karlae & Neoechinorhynchidae & KY077102.1 \\
\hline Neoechinorhynchus brentnickoli & Neoechinorhynchidae & KC004198.1 \\
\hline Neoechinorhynchus schmidti & Neoechinorhynchidae & KY004173.1 \\
\hline Pseudoacanthocephalus nickoli & Echinorhynchidae & KC491889.1 \\
\hline Pseudoacanthocephalus bufonis & Echinorhynchidae & KC491883.1 \\
\hline Pseudoacanthocephalus smalesi & Echinorhynchidae & KC491895.1 \\
\hline Pomphorhynchus zhoushanensis & Pomphorhynchidae & KY472822.1 \\
\hline Polymorphus tereticollis & Pomphorhynchidae & JF706705.1 \\
\hline Pomphorhynchus laevis & Pomphorhymchidae & AY424669.1 \\
\hline Oligacanthorhynchus tortuosa & Oligacanthorhynchidae & AF416417.1 \\
\hline Moniliformis moniliformis & Oligacanthorhynchidae & AF416415.1 \\
\hline Macracanthorhynchus ingens & Oligacanthorhynchidae & AF416414.1 \\
\hline Oncicola venezuelensis & Oligacanthorhynchidae & KU521566.1 \\
\hline Brachionus plicatilis(outgroup) & Brachionidae & AF387206.1 \\
\hline
\end{tabular}

males and almost cylindrical in females, gradually tapering at both ends with occasional antero-dorsal hump. Giant hypodermal nuclei not present. Apical organ prominent, occasionally extending to the posterior proboscis hooks level. Rosethorn-shaped cuticular spines, with discoid base and lobulate margins covering the anterior one-third of the trunk of both sexes, which are arranged in circular rows. There are 3-10 spines in 8-9 circular row with only 4-5 complete circle extending posteriorly to level of past length of proboscis receptacle. The posterior two-thirds of the trunk are bare or may contain a few scattered spines. Proboscis small and short; cone shaped, broadest at base, cylindricalflat anteriorly with 3 circles of hooks, longer than wide. Alternating pattern of anterior, middle and posterior proboscis hook create the illusion of 'five tiers' of hooks on the proboscis. Lateral anterior hooks arched diagonally, robust, markedly larger than other slender hooks. Other hooks project more posteriorly, but do not differ in size, middle hooks slightly longer than posterior hooks and close together. Lateral posterior proboscis hooks slightly longer than other hooks in same circle. Roots of anterior hooks narrow posteriorly; those of middle and posterior hooks truncate posteriorly. Proboscis receptacle cylindrical, singlewalled with large triangular cephalic ganglion at its base (Figure 1A). Unique collar ring on the neck present in both sexes and muscular-like structure on both side of proboscis attach to the ring to support the neck. Neck is smooth, unspined area between the most posterior hooks of the proboscis. Lemnisci cylindrical, long, subequal, with single nucleus in swollen area just posterior to level of proboscis receptacle, usually not reaching anterior testis. Parareceptacle structure (PRS) prominent in both sexes anteriorly. Reproductive structures of both sexes with unusual features. Vagina flanked with paired conical muscular jacket (vaginal sleeve), with broad posterior end inserted at posterior end of trunk and extending anteriorly into body-cavity as reproductive ligament. Some posterior male reproductive structures are extending into bursa.
Male. Trunk 2970.68-4338.86 (3654.77 \pm 967.45$) \times 509.05-$ $718.02(613.54 \pm 147.76) \mu \mathrm{m}$. Proboscis 122.62-192.17 (157.40 \pm $49.20) \times 56.91-106.04(81.48 \pm 34.7)$. Proboscis hooks $43.66-$ 44.44 (44.05 \pm 0.55$)$ in length in anterior circle, 37.46-38.72 $(38.09 \pm 0.89)$ in middle circle, $18.01-18.46(18.24 \pm 0.32)$ in posterior circle. Spine trunk 6.34-6.80 (6.57 \pm 0.33$)$. Proboscis receptacle 260.49-535.90 (398.2 \pm 194.70$)$ x 73.82-147.61 (110.72 $\pm 52.18)$. Collar neck $95.05 \times 11.27$. Anterior muscular-like structure on right $62.94-121.73(92.34 \pm 41.57)$ long and on the left, 66.63-115.47 (91.05 \pm 34.54 ) long. Longer lemniscus; 732.111068.48 (900.3 \pm 237.85$)$, shorter lemniscus 687.64-1012.58 (850.11 \pm 229.77$)$. Testes equatorial, ovoid, contiguous and often overlapping with rounded posterior testis; anterior testis 517.81-600.32 (559.07 \pm 58.34) x 330.11-389.16 (359.64 \pm 41.75); posterior testis 403.23-427.97 (415.60 \pm 17.49$) \times 383.40$ 407.97 (359.69 \pm 17.37 ). Single cement gland with 8 large unfragmented giant nuclei, 252.83-293.03 (272.93 \pm 28.43$) \mathrm{x}$ 205.33-307.32 (256.33 \pm 72.12 ). Cement reservoir just posterior to cement gland, $145.81-502.19(324.0 \pm 251.9) \times 129.31-186.77$ (158.04 \pm 40.63). Saefftigen's pouch 349.54-364.31 (356.93 \pm $10.44) \times 87.93-88.14(88.04 \pm 0.15)$, adjacent to large common sperm duct. Bursa inverted in the trunk 285.79-375.05 (330.42 $\pm 63.12) \times 145.56-248.01(196.79 \pm 72.44)$. Seminal vesicle 304.87446.9 (375.89 \pm 100.43$) \times 98.16-153.55$ (125.86 \pm 39.17$)$.

Female. Trunk $4499.05 \times 432.94 \mu \mathrm{m}$. Proboscis $113.36 \times 64.84$. Proboscis hook length 46.24-50.09 (48.17 \pm 2.72$)$ in anterior circle, $54.09-55.52(53.23 \pm 1.0112)$ lateral hook in anterior circle, 43.73-49.94 (46.84 \pm 4.39$)$ in middle circle, 17.41-20.23 $(18.96 \pm 1.23)$ in posterior circle. Spine trunk length 7.53-8.29 $(7.83 \pm 0.4065)$. Proboscis receptacle $257.53 \times 111.86$. Muscularlike structure on the right 63.70 long and on the left, 62.77 long. Longer lemniscus 839.21 shorter lemniscus 799.92. Reproductive system 634.71 are $15 \%$ of trunk length; uterus $194.23 \times 57.22$ long. Vaginal sleeve $325.06 \times 36.09$. Uterine bell $108.93 \times 55.18$. Selector apparatus $61.18 \times 47.76$. Ovarian ball $32.02-41.68(36.33 \pm 4.913) \times 25.53-35.23(29.8 \pm 4.952)$. Gonopore terminal. 
Description of Acanthogyrus (Acanthosentis) terengganuensis n.sp. Type-host: Barbonymus schwanenfeldii (Bleeker, 1854) (Cyprinidae); Tinfoil Barb; Lampam sungai

Type-locality: Tembat River Kenyir Lake, Terengganu, Malaysia Site of infection: Intestine

Type-specimens: Holotype male and allotype female

Etymology: The new species is named for the state they were found, Terengganu

Voucher specimens: One complete holotype male and one complete allotype female of Acanthogyrus (Acanthosentis) terengganuensis $\mathrm{n}$. sp. were deposited in Pusat Rujukan dan Repositori Laut China Selatan, Insitut Oseanografi \& Sekitaran (INOS), Universiti Malaysia Terengganu (UMT) under collection numbers UMTAcant 0003 (holotype male) and UMTAcant 0004 (allotype female)

Representative DNA sequences: The ITS sequences of Acanthogyrus (Acanthosentis) terengganuensis n. sp. are deposited in the GenBank database under accession number MK 184204

General. Quadrigyridae, Pallisentinae, with characters of Acanthogyrus (Thapar, 1927) and subgenus Acanthosentis (Verma \& Datta, 1929) as diagnosed by Amin (2005). Sexual dimorphism well marked; females are larger than males. Trunk small, curved ventrad, slightly enlarged in middle of males and almost cylindrical in females, gradually tapering at both ends with occasional antero-dorsal hump. Giant hypodermal nuclei not present. Rosethorn-shaped cuticular spines, with discoid base and lobulate margins covering the anterior one-third of the trunk of both sexes, which are arranged in circular rows. There are about 3-10 spines in 10 circular rows with only 2-3 complete circle, separated by unarmed zone, some spine in second region scattered on striated area, same level of lemniscus but not reaching testis. Spines become more widely spaced and somewhat fewer posteriorly occasionally becoming absent ventro-posteriorly. Lemnisci elongate lanceolate, subequal, with single nucleus in swollen area just posterior to level of proboscis receptacle, usually not reaching anterior testis, loose in body cavity with no fibrous connectives to body wall. Parareceptacle structure (PRS) prominent in both sexes anteriorly. Vagina flanked with paired conical muscular jacket (vaginal sleeve), with broad posterior end inserted at posterior end of trunk and extending anteriorly into body-cavity as reproductive ligament. Some posterior male reproductive structures are extending into bursa. Proboscis small and short; globular, as long as wide, more convex anteriorly, with 3 circles of hooks (4 anterior hooks, 2 middle hooks and 12 posterior hooks) (Figure 1B). Alternating pattern of anterior, middle and posterior proboscis hook create the illusion of 'five tiers' of hooks on the proboscis. Anterior hooks robust, markedly

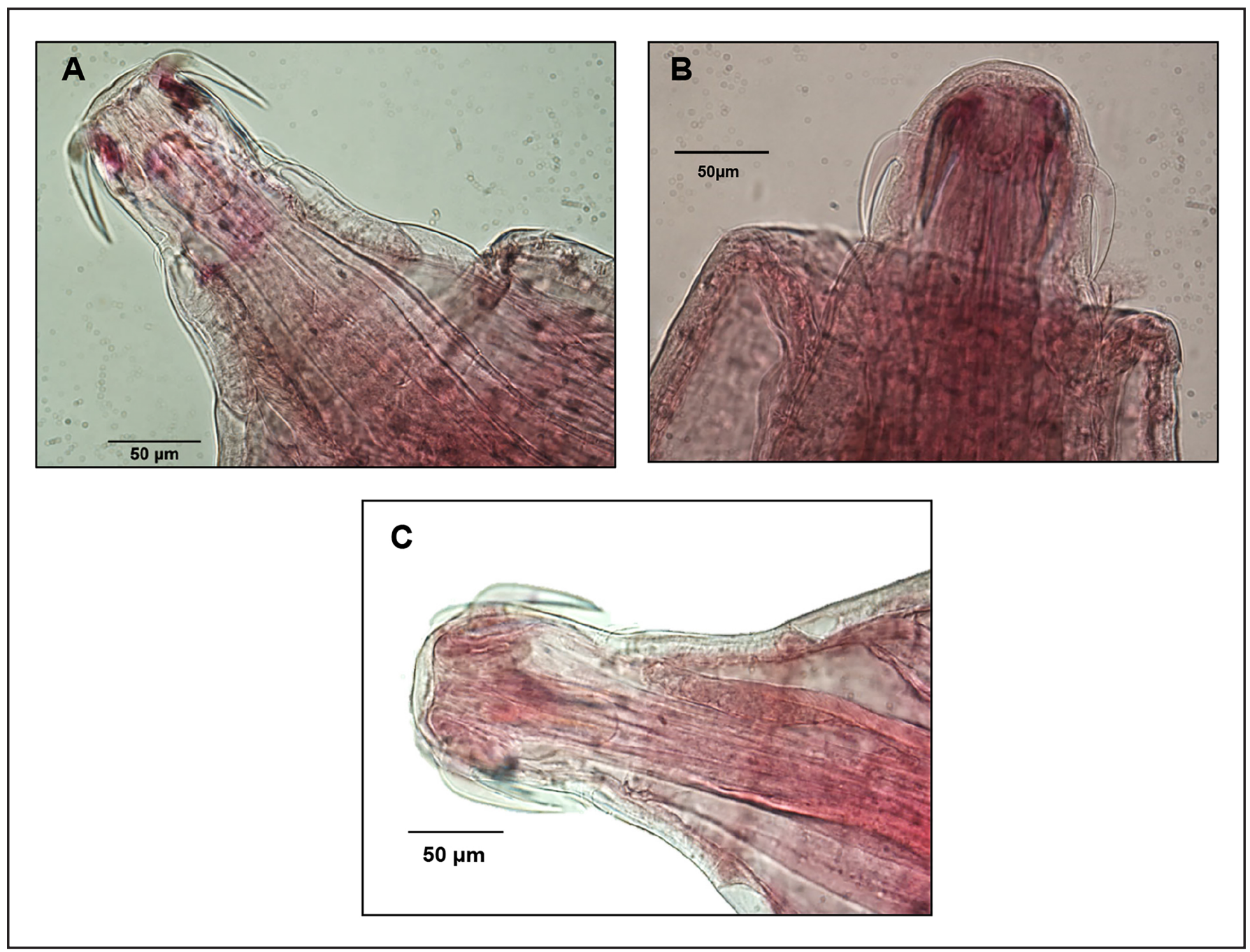

Figure 1. Morphological structure of proboscis; (A) Acanthogyrus Acanthosentis kenyirensis n. sp. (B) Acanthogyrus (Acanthosentis) terengganuensis; (C) Acanthogyrus Acanthosentis tembatensis n. sp. 
larger than other slender hooks. Lateral anterior hooks displaced posteriorly about in the same circle of middle hooks, middle hooks longer than posterior hooks. Roots of anterior hooks narrow posteriorly; those of middle and posterior hooks truncate posteriorly. Proboscis receptacle cylindrical, single-walled with large triangular cephalic ganglion at its base. Unique collar ring on the neck present in both sexes and muscular like structure on both side of proboscis just attach to the ring of the neck.

Male. Trunk $2106.54 \mu \mathrm{m}$ long $\times 327.74 \mu \mathrm{m}$ wide. Proboscis size $54.45 \mu \mathrm{m}$ long $\times 44.40 \mu \mathrm{m}$ wide. Proboscis hooks 40.13 $50.74(44.13 \pm 4.67)$ in length in anterior circle, 35.12-43.49 $(39.31 \pm 5.92)$ in middle circle, $13.95-18.69$ (15.98 \pm 1.62$)$ in posterior circle. Spine trunk 5.20-6.73 (5.79 \pm 0.82 ). Proboscis receptacle cylindrical shape, $190.35 \mu \mathrm{m}$ long $\times 64.51 \mu \mathrm{m}$ wide. Collar neck $80.51 \mu \mathrm{m} \times 12.82 \mu \mathrm{m}$. Muscular-like structures on right $59.52 \mu \mathrm{m}$ long and on the left, $49.50 \mu \mathrm{m}$ long. Longer lemniscus; $510.92 \mu \mathrm{m}$, shorter lemniscus $461.92 \mu \mathrm{m}$. Testes equatorial, ovoid, contiguous and often overlapping, posterior testis wider than anterior testis; anterior testis $291.25 \mu \mathrm{m} \times 213.05 \mu \mathrm{m}$, posterior testis $272.85 \mu \mathrm{m} \times 242.48 \mu \mathrm{m}$. Cement gland with 4-5 large giant nuclei, $143.22 \mu \mathrm{m} \times 127.38$ $\mu \mathrm{m}$. Cement reservoir just posterior to cement gland, 325.48 $\mu \mathrm{m} \times 57.02 \mu \mathrm{m}$. Saefftigen's pouch $287.94 \mu \mathrm{m} \times 74.42 \mu \mathrm{m}$, adjacent to large common sperm duct. Bursa $151.48 \mu \mathrm{m} \times$ $103.01 \mu \mathrm{m}$. Seminal vesicle $273.15 \mu \mathrm{m} \times 62.66 \mu \mathrm{m}$.

Female. Trunk $4121.41 \times 485.75 \mu \mathrm{m}$. Proboscis $87.16 \times 71.49$ $\mu \mathrm{m}$. Proboscis hook length 49.02-50.88 $(50.3 \pm 0.86) \mu \mathrm{m}$ in anterior circle, $42.3-43.29(42.8 \pm 0.7) \mu \mathrm{m}$ in middle circle, $15.22-20.66(19.04 \pm 1.56) \mu \mathrm{m}$ in posterior circle. Spine trunk length 7.58-8.73 $(8.02 \pm 0.62) \mu \mathrm{m}$. Proboscis receptacle 284.07 $\times 109.44 \mu \mathrm{m}$. Muscular- like structure on the right $62.53 \mu \mathrm{m}$ long and on the left $68.28 \mu \mathrm{m}$ long. Longer lemniscus 820.05 $\mu \mathrm{m}$, shorter lemniscus $678.76 \mu \mathrm{m}$. Reproductive system 922.28 $\mu \mathrm{m}$; Uterus $168.25 \times 70.66 \mu \mathrm{m}$ long. Vaginal sleeve $270.29 \times$ $37.14 \mu \mathrm{m}$. Uterine bell $89.41 \times 55.45 \mu \mathrm{m}$. Selector apparatus $65.84 \times 46.34 \mu \mathrm{m}$. Ovarian ball 38.10-41.53 $(39.66 \pm 1.74) \times 31.57-$ 37.59 (35.51 \pm 3.41$) \mu \mathrm{m}$. Gonopore terminal but closer to ventral side.

Description of Acanthogyrus (Acanthosentis) tembatensis n.sp.

Type-host: Barbonymus schwanenfeldii (Bleeker, 1854) (Cyprinidae); Tinfoil Barb; Lampam sungai

Type-locality: Tembat River Kenyir Lake, Terengganu, Malaysia Site of infection: Intestine

Type-specimens: Holotype male and allotype female

Etymology: The new species is named for the location they were found; Tembat River

Voucher specimens: 1 complete holotype male and allotype female of Acanthogyrus (Acanthosentis) tembatensis n.sp. were deposited in Pusat Rujukan dan Repositori Laut China Selatan, Insitut Oseanografi \& Sekitaran (INOS), Universiti Malaysia Terengganu (UMT) under collection numbers UMTAcant 0005 (holotype male) and UMTAcant 0006 (allotype female)

Representative DNA sequences: The ITS sequences of Acanthogyrus (Acanthosentis) tembatensis n.sp are deposited in the GenBank database under accession number MK 184205

General. Quadrigyridae, Pallisentinae, with characters of Acanthogyrus (Thapar, 1927) and subgenus Acanthosentis (Verma \& Datta, 1929) (Amin, 2005). Sexual dimorphism well marked; females are larger than males. Trunk small, curved ventrad, slightly enlarged in middle of males and almost cylindrical in females, gradually tapering at both ends with occasional antero-dorsal hump. Giant hypodermal nuclei present, 5-2. Apical organ prominent, occasionally extending to the same level with posterior hooks. Rosethorn-shaped cuticular spines, with discoid base and lobulate margins covering the anterior one-third of the trunk of both sexes, which are arranged in circular rows. There are about 9 circular rows with only 2 complete circle extending posteriorly to level of past length of proboscis receptacle. The posterior two-thirds of the trunk are bare but may contain a few scattered spines reaching same level with lemniscus. Lemnisci ribbon-shaped, long, subequal, with single nucleus in swollen area just posterior to level of proboscis receptacle, usually not reaching anterior testis. Parareceptacle structure (PRS) prominent in both sexes anteriorly. Reproductive structures of both sexes with unusual features. Vagina flanked with paired conical muscular jacket (vaginal sleeve), with broad posterior end inserted at posterior end of trunk and extending anteriorly into body-cavity as reproductive ligament. Some posterior male reproductive structures are extending into bursa. Proboscis small and short; cylindrical posteriorly rounded hexagonal anteriorly with 3 circles of hooks, longer than wide, broadest at base (Figure 1C). Prominent neck with thick cuticular layer. Alternating pattern of anterior, middle and posterior proboscis hook create the illusion of 'five tiers' of hooks on the proboscis. Proboscis hooks gradually decreasing in length posteriorly. Anterior hooks angulate, robust, and markedly larger than other slender hooks. Two lateral anterior hooks displaced posteriorly to the other frontier anterior hooks in the same circle, but do not differ in size. Middle hooks slightly longer than stubby posterior hooks and close together. Roots of anterior hooks narrow posteriorly; half of blade size, those of middle and posterior hooks truncate posteriorly. Proboscis receptacle cylindrical, single-walled with large triangular cephalic ganglion at its base. Unique collar ring on the neck present in both sexes and muscular like structure on both side of proboscis just attach to the ring of the neck.

Male. Trunk 2556.53-2563.22 $(2559.88 \pm 4.73) \times 417.93-434.76$ $(426.35 \pm 11.9) \mu \mathrm{m}$. Proboscis 71.75-84.58 (78.17 \pm 9.07$) \times 50.10-$ 52.24 (51.17 \pm 1.51$)$. Proboscis hooks 44.10-47.98 (46.04 \pm 2.74 ) in length in anterior circle, 37.95-38.27 in middle circle, 16.02$16.82(16.42 \pm 0.57)$ in posterior circle. Spine trunk 6.65-6.77 (6.71 \pm 0.08$)$. Proboscis receptacle 233.71-273.32 (253.52 \pm 28.01$)$ $\times 80.07-82.61$ (81.34 \pm 1.8$)$. Collar neck 89.72-101.33 (95.53 \pm $8.21) \times 10.89-14.27(12.58 \pm 2.39)$. Muscular-like structure on right 59.14-65.60 (62.37 \pm 4.57$)$ long and on the left, 58.19$61.58(59.89 \pm 2.4)$ long. Longer lemniscus; 516.29-642.73 (579.51 \pm 89.41 ), shorter lemniscus 514.50-605.63 (560.07 \pm 64.44). Testes equatorial, ovoid, contiguous and often overlapping; anterior testis $478.33-483.44(480.89 \pm 3.61) \times 232.63-247.86$ (240.25 \pm 10.8); posterior testis 337.48-466.05 (401.77 \pm 90.91$) \times$ 248.94-273.73 (261.34 \pm 17.53$)$. Cement gland with 5-8 large giant nuclei, $243.20-302.56(272.88 \pm 41.97) \times 157.89-214.61$ $(186.25 \pm 40.11)$. Cement reservoir just posterior to cement gland, 85.57-94.67 (91.12 \pm 5.02) × 97.29-100.56 (98.93 \pm 2.31$)$. Saefftigen's pouch 152.76-285.0 (218.88 \pm 93.5$) \times 33.67-47.61$ (40.64 \pm 9.86$)$, adjacent to large common sperm duct measuring 185.49-229.80 (207.65 \pm 31.33). Bursa 169.85-218.88 (194.37 \pm $34.67) \times 111.55-129.82(120.69 \pm 12.92)$. Seminal vesicle $216.93-$ $283.59(250.26 \pm 47.14) \times 78.21-82.95(80.58 \pm 3.35)$.

Female. Trunk 3202.77-4870.94 (4063.64 \pm 835.37) $\times$ 381.71593.01 (474.24 \pm 108.07) $\mu \mathrm{m}$. Proboscis 80.69-133.13 (114.03 \pm $28.97) \times 64.73-66.43(65.33 \pm 0.96)$. Proboscis hook length 47.42 50.99 (48.95 \pm 1.84$)$ in anterior circle, 42.64-46.76 (44.56 \pm 2.07$)$ in middle circle, $17.39-18.87(18.08 \pm 0.74)$ in posterior circle. Spine trunk length $6.68-7.29(7.02 \pm 0.31)$. Proboscis receptacle 236.59-280.92 (257.44 \pm 22.28$) \times 82.97-94.78(88.64 \pm 5.92)$. Muscular-like structure on the right 63.58-77.51 (70.55 \pm 9.85) 
long and on the left, 56.50-68.08 (62.29 \pm 8.19$)$ long. Longer lemniscus 698.07-810.92 (748.62 \pm 57.34$)$ shorter lemniscus 591.46-733.14 (682.64 \pm 79.12 ). Reproductive system 537.16567.07 (552.12 \pm 21.15 ) are $15 \%$ of trunk length; uterus 168.07 $268.20(205.16 \pm 54.88) \times 63.30-84.09(73.6 \pm 10.4)$ long. Vaginal sleeve 283.69-359.93 $(310.59 \pm 42.79) \times 29.44-39.84(34.78 \pm 5.21)$. Uterine bell 91.11-111.99 $(101.50 \pm 10.44) \times 62.52-95.99(75.29 \pm$ 18.09). Selector apparatus 50.80-66.06 (59.35 \pm 7.8$) \times 30.65$ 48.41 (42.32 \pm 10.11$)$. Ovarian ball 40.41-46.76 (43.59 \pm 4.49$) \times$ 30.30-34.49 (32.40 \pm 2.96$)$. Egg fusiform, elongate, with rounded ends and no polar prolongation of fertilisation membrane. Gonopore terminal but closer to ventral side.

Remarks: The finding of species complexes; Acanthogyrus Acanthosentis kenyirensis.n.sp., Acanthogyrus Acanthosentis terengganuensis $n$. sp., and Acanthogyrus Acanthosentis tembatensis $n$. sp. in this study represents the first record from Kenyir Lake, a new geographical locality reported for this subgenus and species. Most of the other species are found in the Indian subcontinent, few have been reported from China, elsewhere in Asia including Malaysia, African, Europe and Central America. Key to the subgenus Acanthosentis were referred to Amin (2005) and additional key to species in this study.

The species described in this study is a new species with six specific morphology characteristics that differentiate it from the other species. Anterior parareceptacle structure (PRS) (Amin et al., 2007) has been demonstrated in all described species (in this study). PRS was firstly described in Neoechinorhynchus (Neoechinorhynchus) qatarensis (Amin et al., 2002) from Qatar and subsequently in Neoechinorhynchus (Neoechinorhynchus) golvani (Salgado-Maldonado, 1978) from Mexico (Amin et al., 2002, 2011b), Acanthogyrus (Acanthosentis) parareceptaclis (Amin, 2005) from Japan, Neoechinorhynchus ampullata (Amin et al., 2011) and Neoechinorhynchus (Neoechinorhynchus) ascus (Amin et al., 2011) from Vietnam, Acanthogyrus (Acanthosentis) barmeshoori (Amin et al., 2013) from Iran and Acanthosentis kashmirensis (Amin et al., 2017) from Kashmir. Two additional species, Tenuisentis niloticus and Paratenuisentis ambiguus in a third family Tenuisentidae (Van Cleave, 1936) with single-walled receptacle and considerably longer proboscis are now included in the list of acanthocephalans having PRS. The PRS in $A$. (A.) parareceptaclis and in $N$. qatarensis are apparently homologous. Herlyn et al. (2001), however, observed the PRS of P. ambiguous but identified it as "receptacle protrusor muscle extending from the body-wall of the neck to its posterior insertion around the posterior end of the receptacle". The receptacle does not protrude and the structure is certainly not a muscle. The PRS is a tube-like long nucleated structure that runs parallel to the proboscis receptacle in some Eoacanthocephalans with single-walled receptacle. It appears to regulate hydrostatic pressure in the receptacle to facilitate the retraction and eversion of the proboscis in some Eoacanthocephalans with weak single-walled receptacle (Amin et al., 2007).

The second structure is the vaginal sleeve; a paired lateral, cone-shaped, muscular jacket surrounding the vagina. A vaginal sleeve may also be present in another acanthocephalan, A. (A.) tripathi (Rai, 1967) and A. (A.) parareceptaclis (Amin, 2005). Third, is the alternating pattern of its anterior, middle and posterior proboscis hooks. Species of A. (A.) alternatspinus (Amin, 2005) collected from Rhodeus ocellatus ocellatus (Cyprinidae) in Japan and A. (A.) partispinus (Furtado, 1963), collected from Hampala macrolepidota (Valenciennes) (Cyprinidae) in Malaysia, exhibits a similar alternating pattern of anterior and middle proboscis hooks, creating the illusion of 'five tier' of hooks on the proboscis (Furtado, 1963). However, A. (A.) partispinus hooks are considerably longer and the posteriorly displaced lateral hooks of the anterior (60-69 $\mu \mathrm{m}$ long) and middle (26-33 $\mu \mathrm{m}$ long) circles are markedly shorter than the dorsal and ventral hooks of the same circle (anterior 76-85 and middle 57-66 $\mu \mathrm{m})$. In addition, $A$. (A.) partispinus is a larger worm (males 2.32-2.85 × 0.38-0.45 mm), with much larger testes $(340-530 \times$ $120-230 \mu \mathrm{m})$ and spines mostly in the anterior third of the trunk (Furtado, 1963). While in A. (A.) alternatspinus, two lateral proboscis hooks in first and middle circle displaced posteriorly, but have same size of hooks of each circle. It was smaller $(0.96 \times 0.26 \mathrm{~mm})$ compare to $A$. (A.) partispinus with smaller, ovoid and overlapping testes $(125 \times 125)$ and the circle of spine more widely spaces, incomplete dorsally (Amin, 2005).

Moreover, a rare but possibly not exclusive feature of new species of subgenus $A$. (Acanthosentis) sp. is the present of the cuticular collar ring around the neck located between the proboscis and the trunk. The structure looks like ring surrounding the neck with $85.79 \pm 11.42$ long and $11.83 \pm 2$ wide. This has not been observed in other species of Acanthosentis and it is uncertain whether this feature appears in other species of the subgenus. Lastly the presence of muscular-like structure attaches to the collar ring alongside the proboscis to support the proboscis shape while retracts. The proboscis does not invaginate but only retracts completely inside the receptacle and this retracts within the trunk; proboscis maintains shape and hook position.

Total base pair length and GC contents for ITS gene region were $828 \mathrm{bp}$ and $38.0 \%$ for $A$. (A.) kenyirensis n. sp., $837 \mathrm{bp}$ and $40.5 \%$ for $A$. (A.) terengganuensis n. sp., and 820 bp and $43.3 \%$ for $A$. (A.) tembatensis $\mathrm{n}$. sp., respectively. BLAST search for $A$. (A.) kenyirensis n. sp. and $A$. (A.) tembatensis $\mathrm{n}$. sp., showed $84 \%$ and $77 \%$ similarity were identical to Acanthosentis cheni (JX960752.1) respectively. On the other hand, A. (A.) terengganuensis n. sp., were $77 \%$ identical to Neoechinorhynchus golvani (KC004219.1).

The tree with the highest log likelihood (-3130.1149) is shown (Figure 2). The tree is drawn to scale with branch lengths measured in the number of substitutions per site involved 22 nucleotide sequences. All positions containing gaps and missing data were eliminated. There were a total of 219 positions in the final dataset. Base frequencies (f) for $A=0.28599, T=0.28599, C=0.21401$ and $G=0.21401$ were recorded. The substitution model incorporated the following rate matrix $[A-T]=0.0641,[A-C]=0.0641,[A-G]=0.1579,[T-C]=0.1579$, $[T-G]=0.0641,[C-G]=0.0479$ and proportion of invariable sites (Pinvar) $\mathrm{I}=0.00001$. The shape parameter of the discrete gamma distribution was $\mathrm{G}=0.7654$. A total of 608 base pairs from 22 nucleotide sequences of acanthocephalan were analyzed with one outgroup, Brachionus plicatilis. The alignment contains 25 (4.11\%) conserved sites and 576 (94.74\%) variable sites, of which 505 sites (83.06\%) are parsimony informative. The average base composition was $28.4 \%(\mathrm{~T}), 17.3 \%(\mathrm{C}), 30.8 \%(\mathrm{~A})$ and $23.4 \%(\mathrm{G})$. The estimated transition/ transversion (si/sv) ratio, $\mathrm{R}$, is 0.7 .

A total of 22 sequences were assessed for their inter-specific divergence. However, there was only a single ITS sequence for Acanthosentis species available in GenBank. The lowest distance was showed between Pseudoacanthocephalus nickoli and Pseudoacanthocephalus bufonis (0.059/5.9\%) while the highest distance recorded between Brachionus plicatilis and Pomphorhynchus zhoushanensis (0.670/ 67\%). Pairwise comparison between Acanthosentis cheni (JX960752.1) and the new species; A.(A.) terengganuensis, A.(A.) kenyirensis and $A$.(A.) tembatensis from this study showed the genetic distances $30.3 \%, 36.7 \%$ and $42.5 \%$ respectively. 


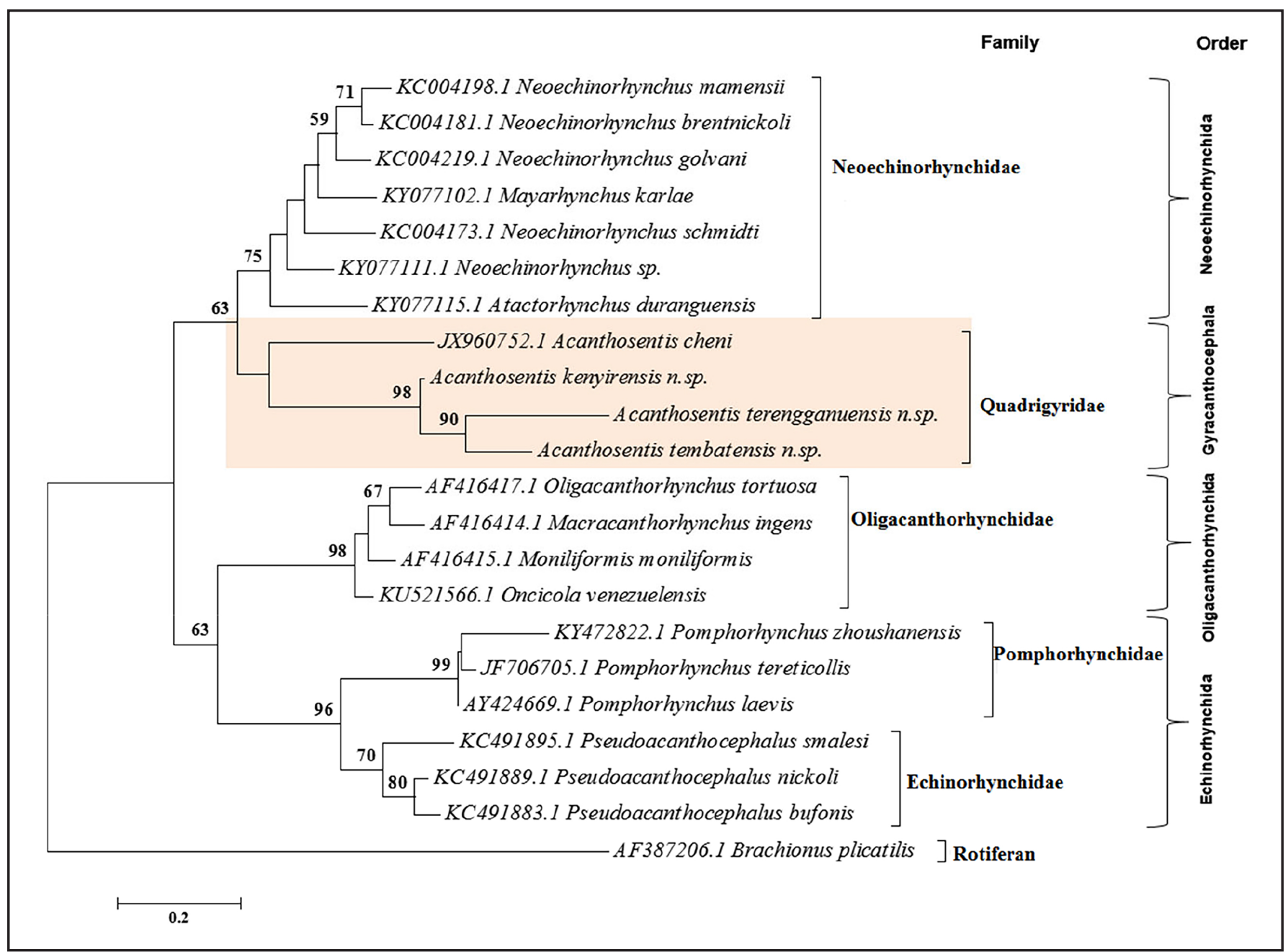

Figure 2. Maximum Likelihood Tree based on T92+G (Tamura 3-parameter) of Internal Transcribed Spacer (ITS) gene sequences of species belonging to Neoechinorhynchida, Gyracanthocephala, Oligacanthorhynchida and Echinorhynchida and Rotifer as an outgroup. Numbers at branches indicate bootstrap support (\%). GenBank accession numbers are provided alongside the species name.

The Maximum Likelihood tree revealed four clades representing four orders (Echinorhynchida, Oligacanthorhynchidae, Gyracanthocephala and Neoechinorhynchida) with five families within (Figure 2). All of the three new species formed a monophyletic group with Acanthosentis chenii (JX960752.1) in the Family Quadrigyridae (Van Cleave, 1920). This clade of Family Quadrigyridae showed a sister relationship with the species in the Family Neoechinorhynchidae (Ward, 1917), supporting a taxonomically close relationship between these two genera. Neoechinorhynchidae typically use freshwater and marine fishes, as well as turtles, as definitive hosts while Quadrigyridae generally use fishes (Amin, 1987; Barger, 2005). Representatives of both families are small, with a singlewalled proboscis receptacle and hooks on the proboscis arranged in six distinct rows, with three hooks in each. Quadrigyridae can be differentiated for having a trunk entirely or anteriorly spined, while Neoechinorhynchidae have an unarmed trunk (Amin, 1987).

\section{DISCUSSION}

This study describes the first report of the genus Acanthogyrus and subgenus Acanthosentis of acanthocephalan fauna from freshwater fish in Kenyir Lake reveal the formation of species complexes in an individual host. Currently, 46 valid species of subgenus Acanthosentis have been described and these studies contribute to the diversity of Acanthosentis worldwide. Species identification and delimitation of acanthocephalans parasite based on their morphological characters is not always feasible or reliable. Formation of species complexes also make it difficult to recognize due to their morphological similarity and lack of characters available for morphological analysis (Schmidt, 1969). According to Anderson et al. (1998), parasitic nematodes have conserved body part with few characters for taxonomic analysis, similar with acanthocephalan that are structurally homogenous and slight anatomical differences between species are often relied upon as the sole criteria of specific identity.

Variability in morphology of all specimens described showed that body shape and size, proboscis receptacle and lemnisci size and male genital organ distribution are showed variable characteristics, while proboscis shape, proboscis hook and size are very stable characteristics from very early stages of development. Body shape and internal organ position change as they grow and according to degree of contraction and accumulation of genital products. Specimen handling during whole mount preparation can also modify general body shape and internal organ position and appearance. In this study, the stable structure like proboscis shape, the number of longitudinal rows of hooks and the length and size of proboscis hooks become the main 
morphological structure to discriminate species compare to the other structure that were unstable. Similar with Huffman and Nickol (1978), they also discovered morphological differences in the length of hooks from a specific region of the proboscis that could be used to diagnose the species. The proboscis shape and the number, size and arrangement of hooks are taxonomic traits that have been traditionally used to classify approximately 1300 described species distributed worldwide (Amin, 1987; Poulin \& Morand, 2004; Kennedy, 2006; Amin, 2013).

New species reported from the family Quadrigyridae with unique morphological variability shows diversity of acanthocephalans in freshwater fish in Southeast Asia especially in Malaysia. These new species is mainly distinguished from the other 46 described species of Acanthosentis by observing the morphological structure and variability in having anterior parareceptacle structure (PRS), vaginal sleeve structure; a paired lateral, cone-shaped, muscular jacket surrounding the vagina, alternating pattern of its anterior and middle proboscis hooks, proboscis shape, the present of the circular collar ring around the neck located between the proboscis and trunk and lastly the present of muscular-like structure attach to the collar ring alongside the proboscis. The acanthocephalans found in the intestine of $B$. schwanenfeldii in Kenyir Lake Malaysia represent new species, namely Acanthogyrus Acanthosentis kenyirensis n. sp., A. (A.) terengganuensis n.sp.and A. (A.) tembatensis n. sp.

Information on acanthocephalan diversity, especially in Malaysia, is fragmentary. Many future studies need to elucidate the thorny-headed worm parasite diversity species in Malaysia. The description of acanthocephalan diversity requires the use of molecular data, since studies that follow an integrative taxonomy approach hold the best promise to obtain more accurate estimate of parasite biodiversity and reach a more stable classification system for the group. In the future, this complex of closely related species could serve as a model system for examination of the factors that drive speciation and also the mechanisms of host and habitat specificity and alternate transmission pathways. Formation of monophyletic group and differences in genetic distance between species of Acanthosentis indicated that the presences of congeneric species complexes

\section{ACKNOWLEDGEMENT}

We would like to thank Lembaga Kemajuan Terengganu Tengah (KETENGAH), staff of AKUATROP Research Laboratory, Institute of Tropical Aquaculture (AKUATROP), Universiti Malaysia Terengganu (UMT) for their assistance and support on this work. Grant research funded by government, Fundamental Research Grant Scheme (FRGS): VOT 59268.

\section{Conflict of interest}

The authors declare that they have no conflict of interest.

\section{REFERENCES}

Anderson, T.J.C., Blouin, M.S. \& Beech, R.N. (1998). Population biology of parasitic nematodes: applications of genetic markers. Advances in Parasitology 41: 220-283. https:// doi.org/10.1016/s0065-308x(08)60425-x

Amin, O.M., Heckmann, R.A. \& Zargar, U.R. (2017). Description of a new quadrigyrid Acanthocephalan from Kashmir, with notes on metal analysis and histopathology, and a key to species of the subgenus Acanthosentis from the Indian Subcontinent. Journal of Parasitology 103: 458-470.
Amin, O.M. (2013). Classification of the Acanthocephala. Folia Parasitologica 60: 273-305. https://doi.org/10.14411/fp. 2013.031

Amin, O.M., Heckmann, R.A. \& Standing, M.D. (2007). The structural functional relationship of the para-receptacle structure in Acanthocephala. Comparative Parasitology 74: 383-387. https://doi.org/10.1654/4257.1

Amin, O.M, Heckmann, R.A. \& Ha, N.V. (2011b). Description of Heterosenti holospinus n. sp. (Acanthocephala: Arhythmacanthidae) from the striped eel catfish, Plotosus lineatus, in Halong Bay, Vietnam, with a key to species of Heterosentis and reconsideration of the subfamilies of Arhythmacanthidae. Comparative Parasitology 78: 29-38. https://doi.org/10.1654/4465.1

Amin, O.M., Saoud, M.F.A. \& Elkuwari, K.S.R. (2002). Neoechinorhynchus qatarensis sp. n. (Acanthocephala: Neoechinorhynchidae) from the blue barred flame parrotfish, Scarus ghobban Forsskål, 1775, in Qatari waters of the Arabian Gulf. Parasitology International 51: 171-176. https://doi.org/10.1016/s1383-5769(02)00011-9

Amin, O. (2005). Occurrence of the subgenus Acanthosentis Verma \& Datta, 1929 (Acanthocephala: Quadrigyridae) in Japan, with the description of Acanthogyrus (Acanthosentis) alternatspinus $\mathrm{n}$. sp. and $A$. (A.) parareceptaclis $\mathrm{n}$. $\mathrm{sp}$. from Lake Biwa drainage fishes and a key to the species of the subgenus. Systematic Parasitology 60: 125-137. https:// doi.org/10.1007/s11230-004-1386-5

Amin, O.M. (1987). Key to the families and subfamilies of Acanthocephala, with erection of a new class (Polyacanthocephala) and a new order (Polyacanthorhynchida). Journal of Parasitology 73: 1216-1219. https://doi.org/10.2307/ 3282307

Amin, O.M., Evans, R.P., Boungou, M. \& Heckmann, R. (2016). Morphological and molecular description of Tenuisentis niloticus (Meyer, 1932) (Acanthocephala: Tenuisentidae) from Heterotis niloticus (Cuvier) (Actinopterygii: Arapaimidae) in Burkina Faso, with emendation of the family diagnosis and notes on new features, cryptic genetic diversity and histopathology. Systematic Parasitology 93: 173-191. https://doi.org/10.1007/s11230-015-9615-7

Barger, M.A. (2005). A new species of Neoechinorhynchus (Acanthocephala: Neoechinorhynchidae) from turtles in Florida, U.S.A. Comparative Parasitology 72: 6-9. https:// doi.org/10.1654/4167

Benson, D.A., Cavanaugh, M., Clark, K., Karsch-Mizrachi, I., Lipman, D.J., Ostell, J. \& Sayers, E.W. (2012). GenBank. Nucleic Acids Research 41: D36-D42.

Berland, B. (2005). Whole Mounts: Occasional Publication No. 1. KUSTEM: Institute of Oceanography, pp. 44.

Furtado, J.I. (1963). On Acanthogyrus partispinus nov. sp. (Quadrigyridae, Acanthocephala) from Malayan cyprinid, Hampala macrolepidota Van Hasselt. Zeitschrift für Parasitenkunde 23: 219-225. https://doi.org/10.1007/ bf00259371

Golvan, Y.J. (1959). Le Phylum des Acanthocephala. Deuxième note. La Classe de Eoacanthocephala (Van Cleave, 1936). Annales de Parasitologie 34: 5-52. https://doi.org/10.1051/ parasite/1959341005

Herlyn, H. (2001). First description of an apical epidermis cone in Paratenuisentis ambiguous (Acanthocephala: Eoacanthocephala) and its phylogenetic implications. Parasitology Research 87: 306-310. https://doi.org/10.1007/ PL00008583

Huffman, D.G. \& Nickol, B.B. (1978). Meristogram Analysis of the Acanthocephalan Genus Pomphorhynchus in North America. Journal of Parasitology 64: 851-859. https://doi.org/ $10.2307 / 3279516$ 
Kennedy, C.R. (2006). Ecology of the Acanthocephala. Cambridge: Cambridge University Press, pp. 249.

Kumar, S., Stecher, G. \& Tamura, K. (2016). MEGA7: Molecular evolutionary genetics analysis version 7.0 for bigger datasets. Molecular Biology and Evolution 33: 1870-1874. https://doi.org/10.1093/molbev/msw054

Luton, K., Walker, D. \& Blair, D. (1992). Comparisons of ribosomal internal transcribed spacers from two congeneric species flukes (Platyhelminthes: Trematoda: Digenea). Molecular and chemical Parasitology 56: 323-327. https://doi.org/10.1016/0166-6851(92)90181-i

Petrochenko, V.I. (1956). Acanthocephala of domestic and wild animals. In Russian: English translation by Israel Program for Scientific Translations, Jerusalem, pp. 465.

Poulin, R. \& Morand, S. (2004). Parasite Biodiversity. Washington D.C.: Smithsonian Institution Press, pp. 216.

Rai, P. (1967). On four acanthocephalan genera parasitic in freshwater fishes with description of three new species. Indian Journal of Helminthology 19: 27-44.
Schmidt, G.D. (1969). Introduction. In: Problems in the Systematics of Parasites, Schmidt, G.D. (editor). Baltimore: University Park Press, pp. 1-5. http://doi.org/10.14411/ fp.2019.012

Tamura, K., Peterson, D., Peterson, N., Stecher, G., Nei, M. \& Kumar, S. (2011). MEGA5: molecular evolutionary genetics analysis using maximum likelihood, evolutionary distance, and maximum parsimony methods. Molecular Biology and Evolution 28: 2731-2739. https://doi.org/10.1093/molbev/ msr121

Taraschewski, H. (2000). Host-parasite interactions in Acanthocephala: A morphological approach. Advances in Parasitology 46: 1-179. http://doi.org/10.1016/s0065$308 \times(00) 46008-2$ 